\title{
SMART MOBILITY IN SMART CITIES
}

\author{
Concepción Moreno Alonso \\ Researcher, ETSI Caminos, Canales y Puertos- Universidad Politécnica de Madrid, Spain \\ Neus Baucells Aletà \\ Researcher, TRANSyT- Universidad Politécnica de Madrid, Spain \\ Rosa M. Arce Ruiz \\ Deputy Director, TRANSyT- Universidad Politécnica de Madrid, Spain
}

\begin{abstract}
Cities are currently undergoing a transformation into the Smart concept, like Smartphones or SmartTV. Many initiatives are being developed in the framework of the Smart Cities projects, however, there is a lack of consistent indicators and methodologies to assess, finance, prioritize and implement this kind of projects. Smart Cities projects are classified according to six axes: Government, Mobility, Environment, Economy, People and Living. (Giffinger, 2007)
\end{abstract}

The main objective of this research is to develop an evaluation model in relation to the mobility concept as one of the six axes of the Smart City classification and apply it to the Spanish cities. The evaluation was carried out in the 62 cities that made up in September 2015 the Spanish Network of Smart Cities (RECI- Red Española de Ciudades Inteligentes). This research is part of a larger project about Smart Cities' evaluation (+CITIES), the project evaluates RECI's cities in all the axes.

The analysis was carried out taking into account sociodemographic indicators such as the size of the city or the municipal budget per inhabitant. The mobility's evaluation in those cities has been focused in: sustainability mobility urban plans and measures to reduce the number of vehicles. The 62 cities from the RECI have been evaluated according to their degree of progress in several Smart Cities' initiatives related to smart mobility. The applied methodology has been specifically made for this project. The grading scale has different ranks depending on the deployment level of smart cities' initiatives.

\section{INTRODUCTION}

As it is well known, the concentration of people, companies and institutions that take place in cities promotes creativity, innovation, diversity and economic growth. Furthermore, the conditions of synergy between different sectors increase the returns to scale becoming a key in the sustainable development of countries. Over $80 \%$ of global GDP is generated in cities, nevertheless, cities has the upper pollution levels worldwide (European Commission, 2015). 
Cities have initiated a transformation process developing strategies to answer the challenges arising from the growing urbanization, demographic change and the new demands resulting from climate change and the natural resources depletion as a result of the growth of urban population. Given these challenges, it is crucial to manage and plan the growth of the city supporting economic growth and competitiveness and by getting social cohesion and environmental sustainability (AMETIC, 2012; ARUP, 2010; Fernandez Güell, 2015). This need involves multiple actors, high levels of interdependence, different fields of action, conflicting goals and, social and political complexity; therefore, it is necessary a holistic and multidisciplinary approach (Abdoullaev, 2011; Fernandez Güell, 2014; Griffinger et al., 2007).

Urban planning in the contemporary period is regarded as the integration of the interests' plurality and active public participation. The situation leads the urban planning into a more participatory approach, with new ways of representing data such as Geographic Information Systems (GIS) and new techniques for participation provided by Information and Communications Technologies (ICT). ICT in urban management and planning are part of concepts such as Digital City or Connected City and the most recent and popular, the term Smart City. Smart City concept differs from the previous emphasizing on environmental and social capital, not only in technology. Smart City concept use ICT to provide a sustainable economic development, tools to manage prudently natural resources and as well as improve our quality of life. ICT's tool are essential to makeover traditional city into a Smart City one. (Abdoullaev, 2011; AMETIC, 2012; Holzer et al. 2006; Nepelski, 2014; Manville et al., 2014; ONTSI, 2015; Telefonica 2011)

The interest in Smart Cities has generated several theoretical discussions, but there is not sufficient progress in the implementation and evaluation of related initiatives. A city that want to implement a Smart initiative should evaluate their needs and establish an integrated approach covering environmental, social and economic aspects (Abella y Ruiz, 2015). Besides, there are rankings based on different attributes related to cities, such as quality of life or environment. So, comparative studies based on the Smart City concept are beginning to emerge (Berrone et al., 2015; Giffinger et al., 2007; Manville et al., 2015; Neirotti, 2012; Moreno, 2016)

Urban mobility has an increasingly important role in urban growth. The implementation of an efficient public transport system can solve part of congestion problems, but Smart Mobility wants to go one step further. Some solutions are based on searching innovative and sustainable ways to provide mobility to people in cities, such as the development of public transport fuels that respect environment, supported by advanced technology and proactive behaviour of citizens (Neirotti, 2012; Van Audenhove et al. 2014) 


\section{2.+CITIES PROJECT}

The project + CITIES is developed in TRANSYT, Transportation Research Centre of the Universidad Politécnica de Madrid, and is funded by the Plan Estatal de Investigación Científica, Técnica y de Innovación 2013-2016 of Ministerio de Economía y Competitividad

Currently, many initiatives are being developed in Spain and also in Europe in terms of Smart City projects (Caragliu et al., 2009; Giffinger et al. 2007; Manville et al., 2014; ONTSI, 2015), however, it needs to be developed indicators and standardized methodologies to evaluate, prioritize, implement and manage this type of projects. It has also identified a lack of visual and easy to use tools for interpreting a large amount of information with respect to these projects. In the 2014 European report: Mapping Smart Cities in the EU, the power of mapping the smart cities situation is appreciated (Manville et al. 2014), Fig. 1 +CITIES go one step further, using map as a dynamic tool to visualise the database, not only a way of representing a static result. +CITIES project provide tools to solve the shortcoming of visual tools and systematic evaluation method for Smart City projects.

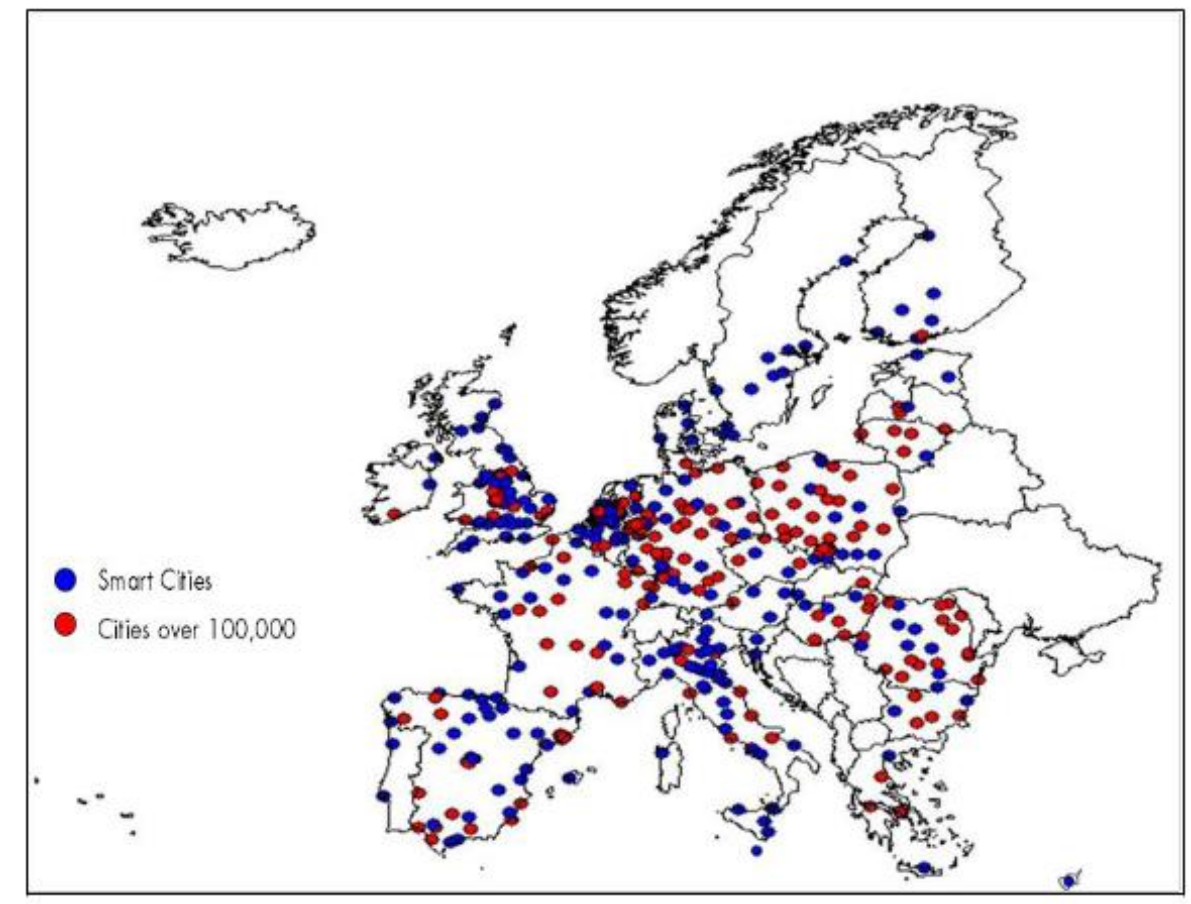

Fig. 1- An example of Map from the European report: Mapping Smart Cities in the EU (Manville et al., 2014)

\subsection{Objectives}

The project aimed to develop a comprehensive framework for assessing mobility projects and urban services, as an advance in knowledge in this field and in defining methods for making informed decisions about smart investment strategies. This system has a great interest to public and private entities to help prioritize, develop and implement Smart City strategies. 


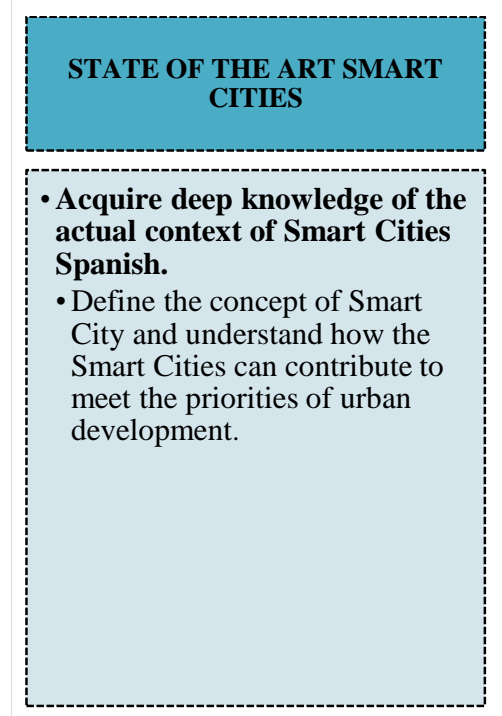

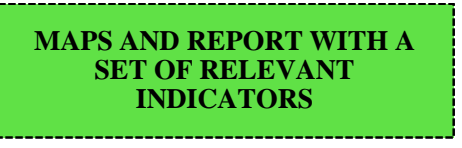

- Make knowledge of the Smart Cities and data accessible through a visual tool (Dynamic Map)

- Characterization of cities through territorial indicators using GIS tools that can help to develope strategies for decision making in Smart City projects.

\section{Fig. 2 - +CITIES Project Structure}

SMART CITY PROJECT EVALUATION MODEL

- Develop a methodology for assessing Smart City projects in the fields of Mobility and

Urban Services

- Develop a methodology to evaluate and prioritize projects Smart City in Mobility and Urban Services

- Develop guidelines to implement and manage Smart City projects, with special focus on Mobility and Urban Services initiatives.

Our project takes into account the expert's point of view to complete the assignment. Thus, it is realized a survey addressed to experts and stakeholders in different topics related to cities. The experts vision from different institutions and countries are essential to reinforce and validate the project.

The expected impact of +CITIES project results is to improve and develop more sustainable practices based on the application of ICT in transportation and urban services. The project focus on the management of the energy consumption and the improvement of mobility making an aiding environment for business and economic activity, in a context of maximum respect for environment and efficient use of resources.

\subsection{Smart Mobility}

Overall, most of the references to mobility are closely related to the improvement of the traffic, but, admitting the importance of it, mobility aspects in a Smart City are not only traffic problems. Basically, a special attention to traffic is a result of the expansion process of cities. This process produced a polycentric structured city with a decentralized, dispersed and fragmented links. This change go along with a larger dependence on private car, due to an increase of distances and a competitiveness public transport in low population density areas (Monzón y de la Hoz, 2009)

The topic of mobility is an important aspect of today's growing cities. The transportation of people and goods within the city is crucial for the development of the economy and the everyday life on it. This issue makes mobility concept bigger than transportation or traffic (Mataix, 2010). The European Commission's establishes different options on which to work (Fig. 3) 
The alternatives to private cars, for example, walking, cycling, public transport or the use of motorcycles.
Increase the efficient travel trought the links between the different modes of transport. Authorities should promote co-modality and assigne more space after mitigate congestion measures.

Fig. 3 - Sketch of European Commission's Green Paper: Towards a new culture for urban mobility (2007)

The importance of mobility and their impact on other pillars of the smart city, such as sustainability, economy and living, make this issue vital for citizens and local governments. A difference between mobility and smart mobility might be the public accessibility to the real time information in order to save time and improve the trip, save money and reduce $\mathrm{CO}_{2}$ emissions as well as connect and guide transport to improve services and provide information to citizens (Manville, 2014). Smart mobility is basic in the smart transformation of cities (Van Audenhove et al., 2014).

\section{METHODOLOGY}

A methodology for evaluating cities has been developed, according to the holistic concept of Smart City. This model has been applied in 2015 to all cities that made up the Spanish Network of Intelligent Cities (RECI), with the aim to contribute to the understanding of the processes of urban transformation from the conventional city into a Smart one.

Smart City evaluation factors
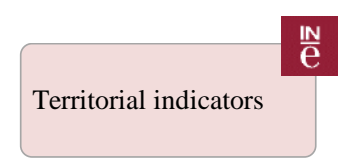

Fig. 4 - General outline of the methodology
Mapping results: ArcGIS Online

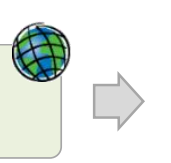

+ CITIES Project

A query tool is born of the merger of a set of information with which a database is created. The purpose of the article is to show the current information of the Spanish cities in the field of Smart Mobility on a dynamic platform. The tool is a fusion of database with a viewing platform. The data used for the tool is classified into two clusters; the first, an assessment model of initiatives Smart City from the point of view of the citizen and secondly some territorial indicators as demographic or economic data of the 62 cities from the abovementioned RECI study.

\subsection{Smart City evaluation factors}

The analysis of mobility involves an evaluation of four factors related to smart mobility. The chosen initiatives are related to:

- Sustainable Urban Mobility Plans 
- Existing measures to reduce the number of vehicles in city

- The use of ICT in traffic management

- The deployment of alternative modes of transport.

Cities studied are the ones that made up the RECI up to September 2015, when the study was closed. This evaluation was carried out by assessing factors related to mobility and transport and taking into account the "citizen experience". The rate has a scale from 0 to 4 which define a factor as Smart (SC) when the factor is above 2, the value 2 means a conventional city (C). Figure 5 shows the factors and the assessment criteria in the mobility area. The website of each council has been visited to find the relevant information and services need to rate the factors. So, the study adds value to statistical information which is the usual source of information in this kind of comparative studies. Finally, a value in Smart Mobility for each city is assigned, this value is the average of factors bellow and thus determine the Smart degree of deployment on Mobility issues.

\begin{tabular}{|c|c|c|}
\hline \multirow{8}{*}{$\begin{array}{l}\text { MOBILITY } \\
(\mathrm{M})\end{array}$} & \multirow{2}{*}{$\begin{array}{c}\text { (m1) } \\
\text { Sustainable Urban Mobility Plans } \\
\text { (SUMP) }\end{array}$} & SC>2: With SMUP \\
\hline & & $\mathrm{C}=2:$ Without SMUP \\
\hline & \multirow{2}{*}{$\begin{array}{c}(\mathrm{m} 2) \\
\begin{array}{l}\text { Payment Integrated in Multimodal } \\
\text { transport system }\end{array}\end{array}$} & SC>2: Smart Card, Smartphone \\
\hline & & $\mathrm{C}=2$ : Impersonal ticket \\
\hline & \multirow{2}{*}{$\begin{array}{c}(\mathrm{m} 3) \\
\text { Deployment of alternative modes }\end{array}$} & SC>2: Integrated payment with Public Transport \\
\hline & & $\mathrm{C}=2$ : Bycicle registration \\
\hline & \multirow{2}{*}{$\begin{array}{c}(\mathrm{m} 4) \\
\text { ICT in traffic control }\end{array}$} & SC>2: ITC integrated \\
\hline & & $\mathrm{C}=2$ : Just basic control \\
\hline
\end{tabular}

\section{Fig. 5 - Valued factors in Smart Mobility}

In a broader context, the other five smart city axes (government, environment, economy, people and living) have been rated according to the same procedure: identification of factors for each axis and defining the respective rating scales. The aim is to obtain an overview of the progress degree of the 62 cities tested in the process of transformation into a Smart City.

\subsection{Territorial Indicators}

Territorial indicators were classified into four groups (see Fig. 6) and the information has been extracted from sources as INE (National Statistics Institute), IGN (National Geographic Institute), websites of the municipalities, 'Anuario' of CaixaBank, Ministry of Finance and Public Administration among others. The database is an extensive set of territorial indicators created for the desired visualization tool. 

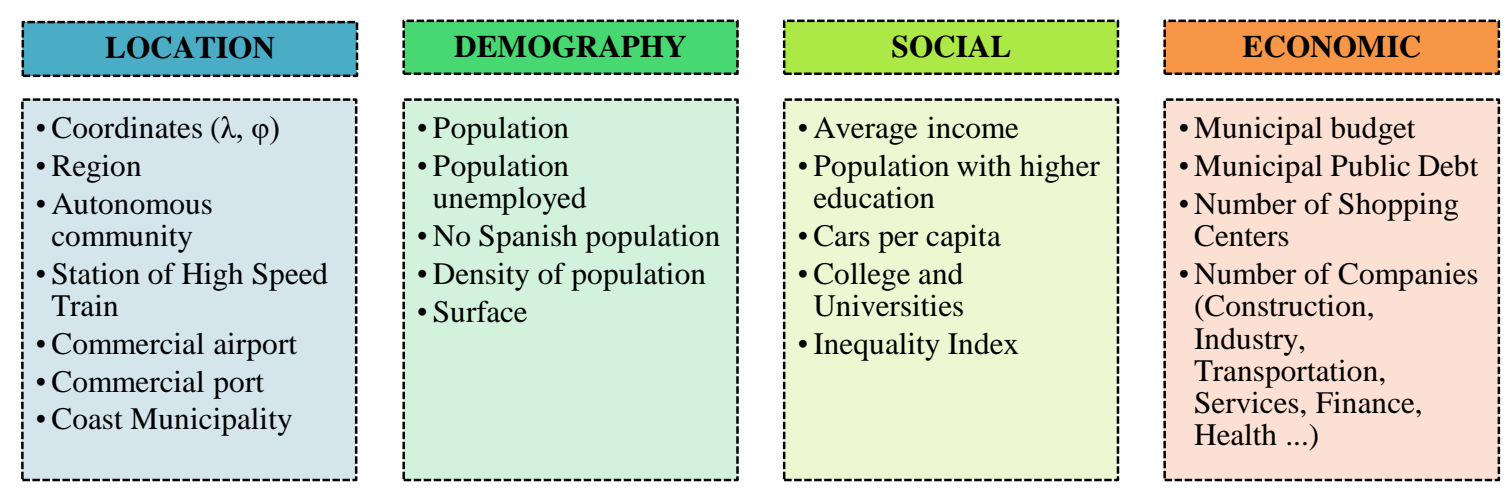

Fig. 6 - Territorial Indicators

\subsection{Mapping Platform}

A visualization tool was made to represent and see the results. The tool combines the RECI's study database and the territorial indicators in a viewing platform. The platform used to visualize the results is ArcGIS Online from the company ESRI. It is a complete, cloud-based mapping platform that make and share beautiful maps, and do everything in between.

\section{RESULTS}

The sample of cities analysed consists of 62 Spanish cities. This set of cities has a population of over 50,000 inhabitants representing 35\% of the Spanish population and $43 \%$ of Spanish population living in municipalities with more than 50,000 inhabitants and moreover includes all Spanish cities with more half a million inhabitants.

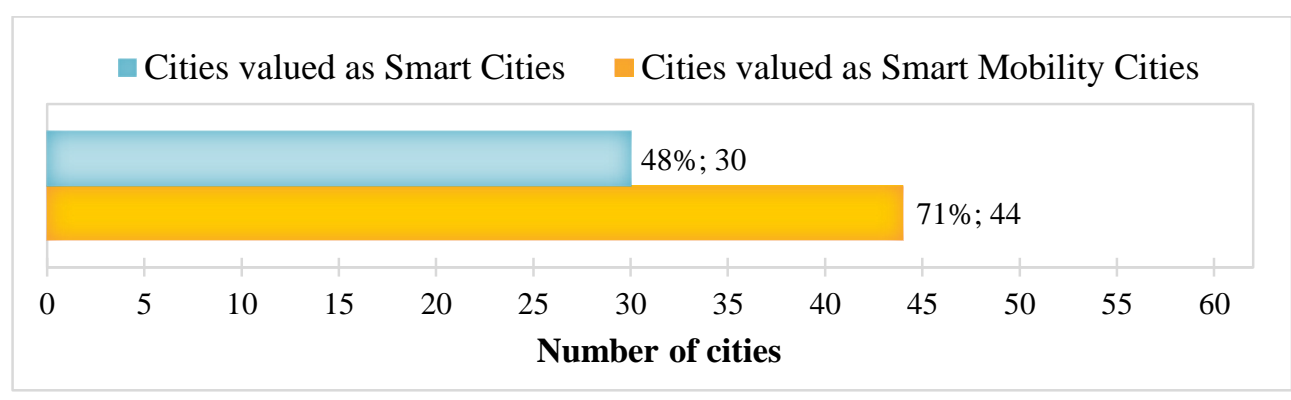

\section{Fig. 7- Smart Cities and Smart Mobility Cities}

The results obtained (Fig. 7) in the overall assessment of the cities show that Smart Mobility is a very relevant actor in a smart city. The mobility factors with higher scores, more than $50 \%$ of cities studied classified as Smart, are the sustainable mobility urban plans and the integration of method of payment in the transport system (Table 1). 


\begin{tabular}{|l|c|c|}
\hline FACTORS ANALYSED & $\begin{array}{c}\text { Number of Smart } \\
\text { Cities (>) }\end{array}$ & \% of cities (RECI) \\
\hline Sustainable Mobility Urban Plans & 44 & $71 \%$ \\
\hline Integrated Payment in Multimodal transport system & 34 & $55 \%$ \\
\hline Deployment of alternative modes & 30 & $48 \%$ \\
\hline ICT in traffic control & 21 & $34 \%$ \\
\hline
\end{tabular}

\section{Table 1- Smart Mobility factors}

There is a wide range of European projects in the Spanish cities in relation to the initiatives of Smart Mobility. PASTA's (Physical Activity Through Sustainable Transport Approaches) project is a an example of an initiative that promotes physical activity through sustainable mobility, connecting transport and health in Barcelona (www.pastaproject.eu). Another initiative is ZEM2ALL (Zero Emissions Mobility To All) in Málaga. It is a pioneer project that tries to give to all citizens the opportunity of having at hand a free emissions mobility in an electric car (www.zem2all.com/en).

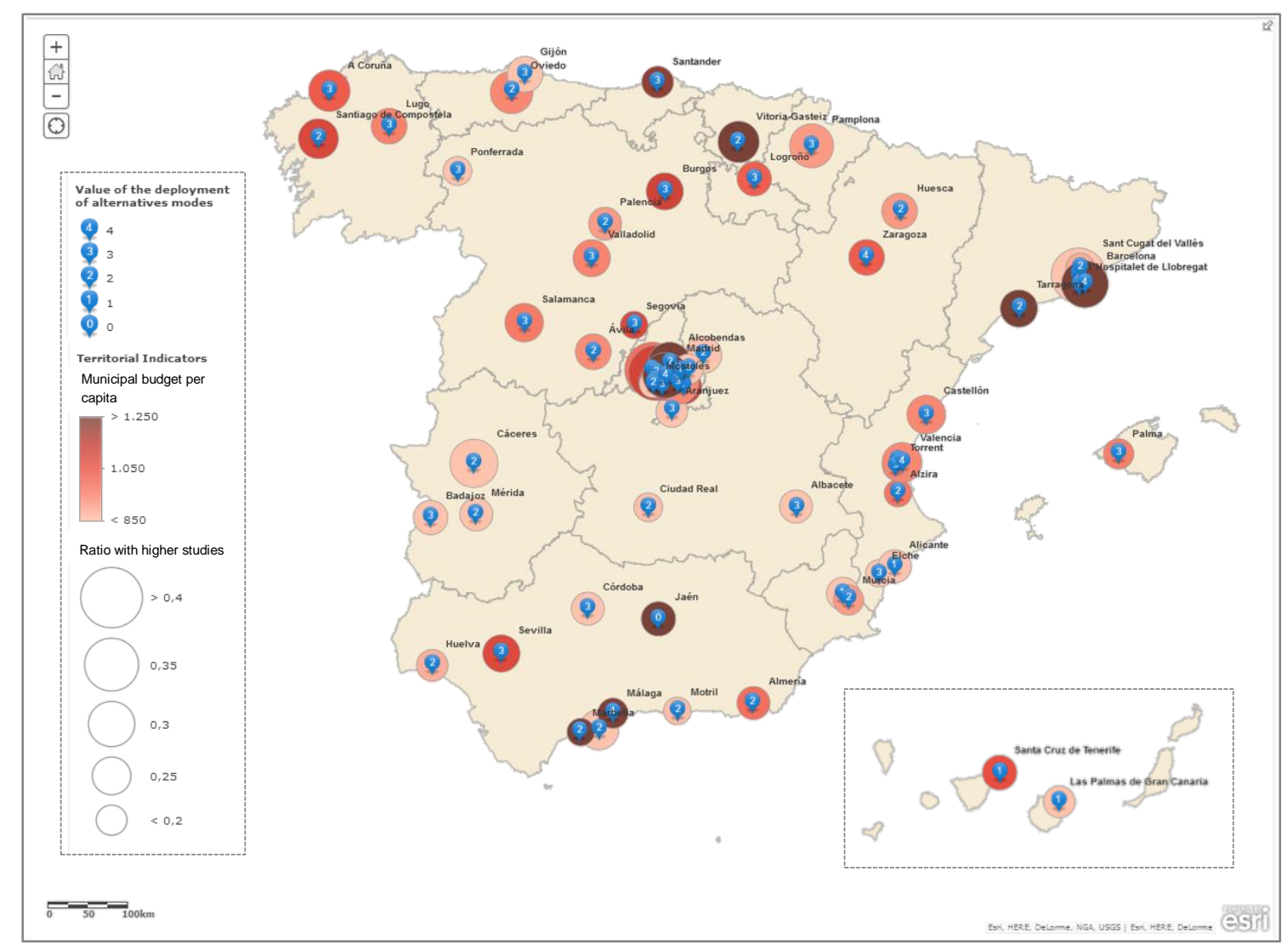

Fig. 8 - Deployment of alternative modes, Municipal budget per capita and population with higher studies

Figures 8 and 9 are exemples of what kind of data can be represented in maps such as the score of a evaluated factor -the deployment of alternatives modes in Figure 8- or if a city is classified as Smart in mobility subjects (Fig. 9). In maps, not only evaluated factors can be apreciated, but also territorial factors such as the motorisation rate, the population, or the municipal budget per person in each city. 


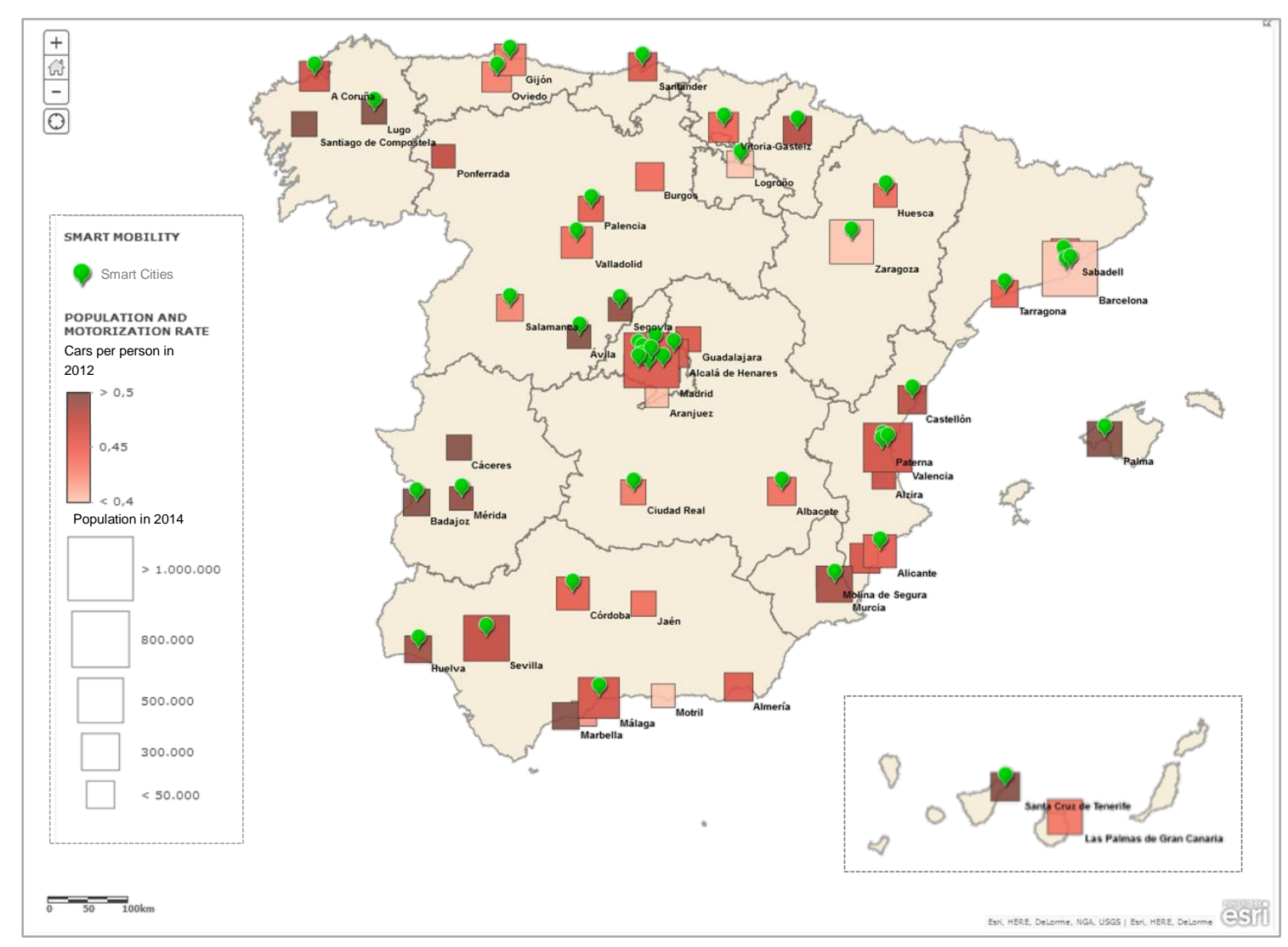

Fig. 9 - Smart Mobility Cities, Population and Motorisation rate

61 out of 62 cities have at least one axis valued as Smart. Also, cities have four Smart axes in the Top Ten Cities in Smart Cities ranking. The best rated cities, with six axes valuated Smart, are Barcelona and Madrid. In Smart mobility, 56 out of 62 cities have at least one factor of mobility valued as Smart. In the Top Ten Smart Mobility ranking, at least three of four factors are Smart. The cities better scored and with the four (mobility) factors Smart are Valencia, Madrid, Barcelona and Sevilla.

\section{DISCUSSION AND CONCLUSIONS}

The process towards getting what is called Smart City is a reality, and, as it can be seen, there is not a single model of Smart City (Moreno, 2016). There are smart cities with diverse natures; cities noted for their innovative commitment, heterogeneous demographics or privileged businesses contexts. Definitely, cities evolve quickly, as technology or society do. The effect of cities on citizens' lives requires good management of cities. In respect to the six axes defining Smart Cities, Spanish smart cities have the best results in mobility and quality of life issues, key aspects in a city for citizens.

The good results obtained in relation to Sustainable Urban Mobility Plans and to multimodal integration of payment indicate the importance of regional and national context in development of Smart Cities. The aid provided by national institutions to cities has been 
crucial to the implementation of the mobility plans. The institutions of regional or metropolitan public transport are also decisive in the multimodal integration factor.

The map described -a visualization tool and dynamic query of the Smart initiatives' status and the features of the cities- aims to be the germ of an observatory of Spanish Smart Cities' situation. The purpose of this tool is to inform through a graphic support advances in the processes of urban transformation into the Smart City concept. The research aims to be expanded in number of analysed cities and, also, in number and type of characteristics that reflect an impact on Smart City concept. The culmination of the project will be a National Monitoring Centre for Spanish Smart Cities to help to prioritize, develop and implement smart strategies.

\section{AGREEMENTS}

Show gratitude to the Ministerio de Economía y Competitividad and Secretaría de Estado de Investigación, Desarrollo e Innovación for funding the project + CITIES through the Plan Estatal de Investigación Científica, Técnica y de Innovación 2013-2016.

Thanks to boost given by the Universidad Politécnica de Madrid in promoting the Smart City philosophy and projects like CIUDAD DEL FUTURO or CAMPUS DEL FUTURO. (http://www.upm.es/institucional/Investigadores/CiudadFuturo).

\section{REFERENCES}

ABELLA, A. Y RUIZ, J.L. (2015). Medida del impacto dela Smart City: gestión de la experiencia ciudadana. Comunicación al I Congreso de Ciudades Inteligentes, Madrid 2425 marzo.

ABDOULLAEV, A. (2011). A Smart World: A development Model for Intelligent Cities" Keynote. The 11th IEE International Conference on Computer and Information Technology (CIT-2011). Paphos, Chipre 2011.

ARUP (2010) Smart Cities: Transforming the 21st century city via the creative use of technology.

AMETIC (2012). Smart Cities. http://ametic.es/es [10/09/2015]

BERRONE, P.; RICART J.E. (2014, 2015) "Cities in Motion- Indice 2014” Centro de Globalización y Estrategia. IESE(2015)

CARAGLIU, A.; DEL BO, C.Y NIJKAMP, P. (2009). Smart Cities in Europe. Proc. 3rd Central European Conference in Regional Science-CERS (2009).

EUROPEAN COMMISSION (2015). Smart Cities and Communities (2015) http://ec.europa.eu/eip/smartcities/ [28/09/2015]

FERNÁNDEZ GÜELL, J.M. (2014). Ciudades y ciudadanos en 2033. La transformación urbana de España. Colección España 2033, Price Waterhouse Coopers. 2014. 
FERNÁNDEZ GÜELL, J.M. (2015).Ciudades inteligentes. La mitificación de las nuevas tecnologías como respuesta a los retos de las ciudades contemporáneas. Economía Industrial 395 p. 17-25. Ministerio de Industria, Energía y Turismo.

GIFFINGER, R.; FERTNER, C.; KRAMAR, H; PICHLER-MILANOVIC, N. Y MEIJERS, E. (2007a).Smart Cities Ranking of European Medium-Sized Cities. Centre of Regional Science, Universidad Tecnológica de Viena, 2007.

GIFFINGER, R.; FERTNER, C.; KRAMAR, H;. Y MEIJERS, E (2007b). City-ranking of European Medium-Sized Cities. Centre of Regional Science, Universidad Tecnológica de Viena, 2007.

HARRISON C.; ABBOTT DONNELLY, I. (2011). A theory of Smart Cities. 55th Annual Meeting of the ISSS (2011)

HOLZER, M.; KIM, S.T.(2006). Digital governance in municipalities worldwide (2005). The e-governance Institute/ The National Center for Public Productivity of the State University of New Jersey- Newark and The Global e-Policy e-Governement Institute of Sungkyunkman University.

MANVIlLE, C.; COCHRANE, G.; CAVE, J.; MILLARD, J.; PEDERSON, J.; THAARUP,R.; LIEBE, A.; WISSNER, W.M.; MASSINK, W.R.; KOTTERINK, B. (2014) Mapping Smart Cities in the EU. Department of Economic and Scientific Policy

MATAIX GONZÁLEZ, C; (2010) Movilidad urbana sostenible: un reto energético y ambiental. Ed. Obra Social Caja Madrid

MORENO ALONSO, C. (2016) Desarrollo de un modelo de evaluación de ciudades basado en el concepto de Ciudad Inteligente (Smart City). PhD Thesis. UPM.

MONZÓN, A. Y DE LA HOZ, D. (2009) Efectos sobre la movilidad de la dinámica territorial de Madrid URBAN. no 14- 2009.

NEIROTTI, P. (2012) Current trends in Smart City initiatives: Some stylised facts. Cities 38 (2014) 25-36

NEPELSKI, D.; DE PRATTO G. (2014) Corporate control, location and complexity of ICT R\&D: A network analysis at the city level Urban Studies 2015, Vol. 52(4) 721-737

ONTSI, Observatorio Nacional de las Telecomunicaciones y de la Sociedad de la Información. Ministerio de Industria, Energía y Turismo (2015) Estudio y Guía Metodológica sobre Ciudades Inteligentes

FUNDACIÓN TELEFÓNICA (2011). Smart cities: un primer paso hacia el internet de las cosas. Fundación Telefónica y Editorial Ariel. Madrid.

VAN AUDENHOVE F.; DAUBY L.; KORNIICHUK O.; POUBAIX J. (2014) Future of Urban Mobility 2.0.Arthur D. Little Future Lab. International Association for Public Transport (UITP) 